\title{
Aborto e Eutanásia: Dilemas Contemporâneos sobre os Limites da Vida
}

| ' Edlaine de Campos Gomes, ${ }^{2}$ Rachel Aisengart Menezes I

Resumo: Este artigo analisa a polêmica em torno da determinação dos limites da vida, a partir do pressuposto de que a demarcação das fronteiras entre vida e morte envolve questôes culturais, sociais, religiosas e políticas referentes à gestão da pessoa. Debates acerca do aborto e da eutanásia evidenciam concepçôes morais sobre os direitos individuais que, por sua vez, são passíveis de normatização em cada contexto. Tais temas revelam - para além da criação e do desenvolvimento de novas tecnologias médicas, direcionadas à reprodução assistida, medicina fetal e manutenção artificial da vida, seja de prematuros ou de doentes fora de possibilidades de cura - valores e posicionamentos, muitas vezes contrastivos. A partir de levantamento de projetos de lei apresentados no âmbito legislativo brasileiro, constatou-se a presença de discursos opostos, oriundos da religião e de defensores da autonomia individual, o que ilustra os dilemas contemporâneos sobre os limites da vida.

> Palavras-chave: Vida; morte; aborto; eutanásia.
${ }^{1}$ Doutora em Ciências Sociais (PPCIS/UERJ); pós-doutora em Antropologia Social (PPGAS/ Museu Nacional/UFRJ); pósdoutoranda do Centro de Estudos da Metrópole (CEM(EBRAP). Endereço eletrônico: edlaineg@gmail.com.

2 Doutora em Saúde Coletiva (IMS-UERJ); pós-doutora em Antropologia Social (PPGAS/ Museu Nacional/UFRJ); pesquisadora associada do Centro Latino-americano em Sexualidade e Direitos

Humanos (CLAM/IMS-UERJ).

Endereço eletrônico:

raisengartm@terra.com.br. 
Este artigo aborda a determinação dos limites da vida: início e término. Partimos do pressuposto de que a demarcação das fronteiras entre vida e morte envolve questôes culturais, sociais, religiosas e políticas referentes à gestão da pessoa. Concepçôes diversas sobre o significado da "pessoa humana", seu estatuto e direitos elucidam aspectos que integram a polêmica acerca dos desígnios do início da vida, do aborto, da morte e da eutanásia. Tais temas revelam, para além da criação e do desenvolvimento de novas tecnologias médicas - direcionadas à reprodução assistida, à medicina fetal e manutenção artificial da vida, seja de prematuros ou de doentes fora de possibilidades de cura - valores e posicionamentos, muitas vezes contrastivos, acerca dos direitos individuais.

Para abordar a temática, inicialmente apresentamos o processo de constituição de verdades no Ocidente, baseadas na ciência que, por sua vez, fundamenta o saber e a prática médica. No século XX, o desenvolvimento de tecnologias aplicadas tanto à concepção quanto ao prolongamento da vida indicou a necessidade de elaboração de leis sobre os limites da vida. Examinamos as conexões entre os dispositivos médicos e jurídicos, especialmente acerca do aborto e da eutanásia. A seguir, são examinadas proposições de lei apresentadas em três Casas Legislativas (Câmara Federal e Assembléias Legislativas dos Estados do Rio de Janeiro e de São Paulo), com o intuito de evidenciar os posicionamentos em torno do direito individual de intervenção nos limites da vida. ${ }^{1}$ Essas propostas constituem exemplos significativos sobre a tensão entre valores laicos e religiosos, na formulação de leis no Brasil. Por fim, tecemos considerações acerca das dificuldades de demarcação dos limites da vida na sociedade ocidental contemporânea, regida tanto pela liberdade religiosa quanto pela autonomia individual.

\section{Início e término da vida}

Vida e morte são conceitos centrais para a compreensão das concepções de pessoa presentes em distintas culturas. Todo grupo social constrói sua própria definição de pessoa (MAUSS, 2003b; DUMONT, 1985; DUARTE, 2003) ${ }^{2}$ e, conseqüentemente, delimita o período em que o indivíduo passa a ser - e deixa de ser - reconhecido como tal. Os modos de administração do início e término da vida são os mais diversificados e dependem das crenças compartilhadas elaboradas por cada grupo social. Em cada contexto, dependendo da concepção dominante, são produzidas práticas coletivas e individuais, que suscitam sentimentos e interpretações 
as mais diversas, em torno do nascimento e da morte. Como exemplo, podemos citar certos grupos australianos que consideram naturais mortes tidas como violentas em sociedades ocidentais (MAUSS, 2003a, p. 352). Para eles, um ferimento, assassinato ou fratura são causas naturais. Já os Azande consideram que um feitiço provoca a morte da pessoa (EVANS-PRITCHARD, 1985). Seja na Nova Zelândia, seja entre os Azande, o que está em jogo são as distintas formas de mobilização e de definição de natureza, nos diferentes contextos e construçôes sociais.

Apesar das diferenças, a determinação dos limites de vida e morte é regida, no Ocidente, por uma lógica análoga à construída por outras culturas. Na sociedade ocidental moderna, ${ }^{3}$ vida e morte podem ser concebidas segundo posicionamentos religiosos, fundamentalmente pautados pela tradição judaico-cristã (DUARTE; GIUMBELLI, 1994). A perspectiva científica é, concomitantemente, uma relevante interlocutora. Pode-se aplicar aqui a idéia de Mauss (2003a), da preeminência das "causas coletivas precisas", conceito usado em sua análise da "morte sugerida pela coletividade" - que atribuem ao indivíduo ações da moral que atingem, de modo marcante, o físico. Na cultura ocidental moderna, há uma crença generalizada na ciência/razão como método de leitura objetiva da natureza (CAMARGO JR, 2003, p. 102). A concepção de pessoa específica da cosmologia moderna, fundada no individualismo, conjuga subjetivismo e naturalismo. ${ }^{4} \mathrm{O}$ subjetivismo se refere à presumida primazia da escolha pessoal do sujeito, incluindo-se as experiências religiosas do mundo contemporâneo; já o naturalismo atribui à natureza um papel fundamental na ordenação dos horizontes modernos:

trata-se, evidentemente, de uma valorização nova e radical da realidade física do mundo, apreensível pela razão humana (vista, ela própria, como natural) e oposta à preeminência cristã tradicional da sobrenatureza e da transcendência moral (DUARTE et al., 2006, p. 22).

A partir do século XVIII, a definição de vida e morte passou a pertencer ao saber médico, fundado na ciência e, mais especificamente, na biologia. $\mathrm{O}$ processo de secularização (WEBER, 1992) e a crescente medicalização do social (MENEZES, 2004, p. 28), ao menos em termos ideal-típicos, deslocaram a definição e a determinação dos limites da vida e da morte, da esfera religiosa para o domínio da ciência. A organização de uma estrutura lógica altamente racionalizada de produção de "verdades" sobre o universo tornou-se o eixo preeminente (FOUCAULT, 1977; CAMARGO JR, 2003, p. 107). 
No decorrer do século XX, em especial em sua segunda metade, houve significativo desenvolvimento de novas tecnologias aplicadas à área médica, o que contribuiu para uma exacerbação do debate em torno das fronteiras da vida e da morte. A criação do respirador artificial, de aparelhagem para manutenção artificial da vida (MENEZES, 2006) e de métodos de visualização fetal (CHAZAN, 2005) determinou a elaboração de novas definições dos critérios de vida e morte pelo aparato médico, jurídico e científico. $\mathrm{O}$ advento de tecnologias para manutenção do funcionamento de órgãos vitais, com o suporte oferecido pelo uso das novas aparelhagens, tornou possível o prolongamento da vida de adultos e de bebês prematuros. Em menos de duas décadas, foram implementadas técnicas que possibilitaram - e difundiram - a reprodução assistida e os transplantes de órgãos vitais (LUNA, 2007; LOCK, 2002).

Estudos antropológicos acerca dos limites da vida - início e final - apontam diferenças e semelhanças no que concerne ao estatuto de pessoa nos dois casos. Tanto o embrião/feto quanto o doente terminal - mais especificamente, com morte encefálica - podem ser caracterizados por estarem situados em um tempo indeterminado e provisório (KAUFMAN; MORGAN, 2005). Nos termos de Turner (1974), trata-se de uma condição liminar. No entanto, no início da vida há um processo de reconhecimento da condição social da pessoa, ao passo que no período final se dá uma transformação do estatuto - de um ser vivo para outra instância - cadáver, espírito, ancestrais, entre outras possibilidades, de acordo com o referencial cosmológico. A partir do estabelecimento da nova condição, as relações sociais entre a pessoa (emergente ou em declínio) e o contexto no qual está inserida são reorganizadas.

O tema dos direitos passa a integrar a pauta de debates, que se referem aos usos do próprio corpo e de substâncias corporais humanas, como posse e uso de óvulos, esperma, embriōes congelados, células-tronco embrionárias, prolongamento ou não da vida de doentes graves e terminais, interrupção de gestação e doação de órgãos, entre outros. Na polêmica, duas posições se destacam: da sociedade laica e da religião. A gestão social, médica e jurídica em torno da determinação dos limites da vida sofre influências de vertentes religiosas e da sociedade civil, representada especialmente pelas organizaçôes não-governamentais e movimentos sociais voltados aos direitos humanos, sexuais e reprodutivos. 
O aborto e a eutanásia cada vez mais se apresentam como questôes centrais na contemporaneidade, por indicarem não apenas a delimitação das fronteiras entre vida e morte, mas por constituírem temas que revelam tensões quanto à noção de pessoa no Ocidente e seus direitos. Uma distinção se faz necessária, no que concerne à possibilidade de escolha: o nascituro é incapaz de se manifestar, de modo que o direito de escolha é atribuído a outro - à mãe, ao Estado ou a instâncias religiosas. No caso do doente terminal, as demandas se relacionam à concessão do direito de escolha em relação aos desígnios da própria morte.

De acordo com Diniz (2006a), de todos os temas da bioética, as situações relacionadas ao início e ao fim da vida são as que mais intensamente mobilizam posicionamentos da saúde pública - seja em relação ao aborto como causa de mortalidade materna (DINIZ, 2007, p. 1992), seja na assistência ao último período de vida. Para Duarte (no prelo), uma ativa frente de preocupação quanto ao estatuto da pessoa nas sociedades contemporâneas concerne à condição do embrião e do feto humanos. A questão do aborto é particularmente exemplar, ao contrapor diferentes níveis de atualização da pessoa, conforme se privilegie o nascituro isolado de seu contexto materno ou se defenda o direito da mulher de gerir seu corpo. Outra questão importante, que impõe novas abordagens, é o crescente envelhecimento populacional, exigindo uma redefinição do conceito de morte: de um tabu moral para uma questão emergente de saúde pública e de direitos individuais (DINIZ, 2006b, p. 1.742).

\section{Determinação de vida e dispositivo médico e jurídico}

Os dispositivos provenientes do saber médico são centrais no debate em torno do aborto e da eutanásia, seja em posiçôes favoráveis ou contrárias à legitimidade de tais práticas. A determinação do início da vida de uma pessoa - e seus direitos - constitui objeto de debate, tanto no âmbito médico e científico quanto na sociedade em geral. A utilização de tecnologia para manutenção da vida em ambiente artificial extra-uterino, em unidades intensivas neonatais, ampliou os critérios de viabilidade do recém-nascido pré-termo, de modo que cada vez mais é possível preservar a vida de nascituros com baixo-peso ou tempo de gestação. Com as técnicas de reprodução assistida discutem-se os direitos de posse e uso de óvulos, esperma, embriôes congelados e células-tronco embrionárias. Esses temas estão centrados no mesmo ponto, também atinente 
à polêmica do aborto: a determinação do momento do início da vida (SALEM, 1997; LUNA, 2001 e 2007).

Na contemporaneidade, a discussão sobre o estatuto do embriāo ou a "condição fetal" (LUNA, 2002; BOLTANSKI, 2004) encerra disputas acaloradas, que abrangem aspectos jurídicos, éticos e religiosos. A controvérsia acerca do aborto se estabelece neste contexto com os seguintes antagonismos principiais: de um lado, a viabilidade da vida extra-uterina - certa autonomia do feto em relação ao corpo da mãe, conferida pelos saber e tecnologia médicos -, e de outro, a autonomia da mulher, relativa a seu próprio corpo, configurada pelo movimento pelos direitos sexuais e reprodutivos das mulheres. Oponentes da interrupção da gravidez argumentam que o feto não se distingue de um recém-nascido. Já os que defendem a possibilidade de interrupção da gestação tendem a focar a questão nos direitos da mulher, e não no limite ético de definição da vida (HOWARTH; LEAMAN, 2001, p. 1).

$\mathrm{Na}$ mesma direção, sobre o início da vida está posicionada a polêmica em torno da eutanásia. Até a segunda metade do século XX, o paradigma que regeu a definição da morte centrava-se na parada dos batimentos cardíacos e da respiração. Conseqüentemente, a condição de pessoa viva era definida pelo funcionamento de seu sistema cardíaco e respiratório. No final do século XIX e início do XX, médicos descreveram casos de pacientes que apresentavam um quadro neurológico, denominado em 1959, por Mollaret e Goulon, de coma irreversível (coma depassé) (LOCK, 2004, p. 138), um quadro clínico caracterizado por ausência de funcionamento cerebral e manutenção das funções dos outros órgãos e sistemas. Com o advento de tecnologias para a manutenção do funcionamento de órgãos vitais, torna-se possível o prolongamento da vida e, a partir dos anos 1970, são implementadas técnicas que possibilitam transplantes destes órgãos, doados por pacientes considerados em estado de "coma irreversível".

A necessidade de estabelecer novos critérios de definição de morte torna-se então premente, uma vez que não é mais possível referir-se apenas à parada cardiorrespiratória. Em 1968, um grupo de médicos de Harvard reúne-se com um advogado, um teólogo e um historiador, para examinar problemas éticos relacionados a esta condição clínica e à doação de órgãos para transplante. O Comitê de Morte Cerebral de Harvard publica um relatório, estabelecendo duas definições de morte: a "tradicional" cardiopulmonar e a morte cerebral (ou encefálica). Nos 
anos 1970, essa definição foi ampliada por diversos artigos em revistas médicas norte-americanas e européias, que debatiam os testes clínicos para diagnosticar a morte cerebral (LOCK, 2004, p. 139). Em 1981, havia seis diferentes tipos de estatuto de morte cerebral nos Estados Unidos, o que evidenciava a necessidade urgente de consenso no meio médico. Uma nova comissão foi então estabelecida em Harvard para discutir o tema. O relatório refletiu sobre a definição da morte de um ser humano, não considerando esse estatuto dependente apenas da morte de células, tecidos e órgãos.

A comissão preocupou-se em tratar do significado social da morte: o que estava em jogo eram as definições de pessoa, de processo de morte e de funções cerebrais. A revisão dos critérios que determinam a morte de uma pessoa implica redefinição do estatuto do ser humano, não se restringindo apenas às determinaçóes legais. A partir dessa revisão, cria-se um novo estatuto de pessoa e de vida, no qual a identidade pessoal está centrada na mente ou, em outros termos, na função cerebral ou encefálica (LOCK, 2002, p. 3). Os critérios de delimitação da vida e da morte utilizados pelo Comitê foram os dominantes nos Estados Unidos e Europa ocidental, em países em que a crença na medicina é praticamente hegemônica. ${ }^{5}$

A maior parte dos países do Ocidente, em datas distintas, adotou oficialmente os critérios de Harvard. No Brasil, o Conselho Federal de Medicina aprovou a Resolução CFM no 1.480, em 8 de agosto de 1997, estabelecendo novos critérios de constatação de morte encefálica (FRANÇA, 2004, p. 329). Foi instituído um termo de declaração de morte encefálica, onde devem constar a identificação da causa do coma, o resultado do exame neurológico, as assinaturas dos profissionais que procederam ao exame clínico, os exames complementares e as observações que indicam as recomendações para a prática dos diversos exames e testes. A partir desse registro, é possível a autorização de familiares (no caso de não haver registro do desejo do paciente) para retirada de órgãos para doação.

A determinação dos limites da vida e da morte envolve desígnios jurídicolegais, passíveis de interpretações e interesses diversos. A decisão de interromper a manutenção da vida por meio artificial causa grandes controvérsias a cada vez que não há consenso familiar ou na própria equipe médica, acerca desse procedimento. A possibilidade de prolongamento da vida com os recentes avanços tecnológicos coloca em foco o debate em torno da eutanásia, definida como a interrupção da vida, causando a morte de alguém com doença terminal ou 
incurável. A eutanásia ativa envolve uma ação médica, como administração de injeção letal; e a passiva usualmente se refere à omissão de recursos, tais como medicamentos, hidratação e alimentação. A eutanásia pode ser voluntária, segundo o desejo expresso pelo doente, ou involuntária, quando a pessoa está incapacitada de dar consentimento. No âmbito do debate em torno da interrupção da vida há ainda outra categoria, o suicídio assistido. Ele se distingue da eutanásia pelo sujeito que executa a ação: o próprio doente comete o ato, utilizando drogas prescritas pelo médico com este propósito (HOWARTH; LEAMAN, 2001, p. 177).

A eutanásia é permitida na Holanda, desde 2001, e na Bélgica a partir de 2002. No território norte da Austrália, vigorou uma legislação permitindo a eutanásia voluntária ativa de 1995 até 1997, quando o Parlamento Federal embargou a lei. A maioria dos estados dos Estados Unidos e do Canadá possui legislações que permitem aos médicos a suspensão de tratamentos com a autorização do paciente ou de seu representante. O estado norte-americano do Oregon aprovou uma lei, em 1999, que permite o suicídio assistido por médicos. No Brasil, tanto a eutanásia quanto o suicídio assistido são consideradas práticas ilegais e, conseqüentemente, passíveis de exame pelo Poder Judiciário.

Em diversos países, como Estados Unidos e Inglaterra, os defensores da legalização do aborto e da eutanásia se unem, pelo fato de ambas as questôes envolverem a discussão do estatuto da vida, da autonomia individual e dos direitos sobre a vida. Os debates estão sendo travados no mundo ocidental por grupos de interesse e movimentos políticos e religiosos, buscando influenciar a reforma das legislaçôes vigentes sobre tais temas. Os que se opõem à eutanásia argumentam que cabe aos profissionais de saúde cuidar e, conseqüentemente, investir com a finalidade de salvar vidas, ao invés de provocar a morte. Em especial, os médicos que prestam assistência em Cuidados Paliativos (MENEZES, 2004) são contrários à eutanásia, por considerar que as demandas de doentes terminais por esta intervenção somente ocorrem devido a uma assistência em saúde precária (HENNEZEL, 2000 e 2004). Paralelamente, condenam a eutanásia os movimentos baseados em crenças religiosas, que afirmam a santidade da vida, argumentando que, uma vez aceita, a prática da eutanásia involuntária especialmente no caso de idosos - em certo tempo se tornará viável, por pressões econômicas (DINIZ, 2006a, p. 1.739). 
No Brasil, a discussão sobre o "morrer bem", medicamente administrado, conduziu à aprovação da Resolução no 1.805/2006, em 28 de novembro de 2006, pelo Conselho Federal de Medicina, nos seguintes termos:

$\mathrm{Na}$ fase terminal de enfermidades graves e incuráveis é permitido ao médico limitar ou suspender procedimentos e tratamentos que prolonguem a vida do doente, garantindo-lhe os cuidados necessários para aliviar os sintomas que levam ao sofrimento, na perspectiva de uma assistência integral, respeitada a vontade do paciente ou de seu representante legal.

Esta decisão provocou debates na mídia, como a matéria do jornal Folha de S. Paulo, de 4 de dezembro de 2006, que cita o posicionamento favorável da Confederação Nacional de Bispos do Brasil, "afirmando que a prática da ortotanásia, feita com sério discernimento, representa a aceitação da condição humana diante da morte”. Em 27 de novembro de 2007 a Justiça Federal suspendeu, por uma liminar, esta Resolução, baseada na caracterização "de crime de homicídio", nos termos do artigo 121 do atual Código Penal (Folha de São Paulo, Cotidiano, 27/11/2007).

O Conselho Federal de Medicina refuta qualquer semelhança entre ortotanásia e eutanásia. Cabe esclarecer a definição do primeiro conceito, defendido pelos médicos, que surgiu em oposição à distanásia (prolongamento do processo do morrer, com sofrimento, ou encarniçamento terapêutico): não-prolongamento artificial do processo de morte, além do que seria o processo natural. Em termos ideais, a ortotanásia deve ser praticada pelo médico responsável, que acompanha um doente em processo natural de morte. Ela é conduta atípica frente ao Código Penal, pois não é causa de morte, uma vez que o processo já estaria instalado. Cabe ressaltar que a delimitação do processo natural de morte é passível de discussão em âmbito médico e jurídico. No que concerne à Igreja Católica, a Conferência Nacional dos Bispos do Brasil não faz objeções à ortotanásia. Segundo o secretário-geral da instituição, Dom Odilo Pedro Scherer, a prática já era aceita pela Igreja desde a década de 1950: "Quando a morte já se anuncia como inevitável, a decisão de renunciar a possíveis excessos terapêuticos que somente dariam um prolongamento precário e penoso pode ser considerada legítima."

Há semelhanças e especificidades quando o tema é o aborto. A reforma da legislação invoca posicionamentos diversos, compostos por valores distintos, que se visibilizam e se consolidam a partir deste contraste. No Brasil, parte significativa 
dos principais representantes dessas correntes no legislativo transita e influi nas decisōes relativas aos dois temas. Como na eutanásia, o discurso médico-científico também é acionado para dar sustentação a argumentos favoráveis e contrários à ampliação dos permissivos legais, seja no Brasil ou em outros países do Ocidente (DUARTE et al., 2006).

A Igreja Católica, ao contrário das brechas possibilitadas por propostas como a ortotanásia, permanece investindo em seu posicionamento contrário a qualquer modalidade de aborto. No entanto, Gomes (2007) evidencia, em artigo recente, que a posição acerca da questão não conforma consenso entre as igrejas protestantes. Toma como exemplos os casos da Igreja Presbiteriana do Brasil (IPB), Igreja Metodista (IM) e Igreja Universal do Reino de Deus (IURD). Embora as três reiterem o "valor divino da vida", cada uma relativiza, a seu modo, a aplicação desta premissa. A IPB se manifesta contrária à descriminalização do aborto, mas considera legítimo o procedimento para salvar a vida materna. A IM amplia as possibilidades, ao avaliar também como legítimos o aborto em casos de estupro, e quando se comprova a inviabilidade de sobrevivência do feto. A autora conclui que as possibilidades de diálogo se abrem quando as igrejas, principalmente as protestantes, expõem seus posicionamentos oficiais, que possuem sensíveis diferenças.

No Brasil, no que tange à atenção ao abortamento, observa-se que à área da saúde também é atribuído um papel central e extremamente relevante neste processo. $\mathrm{O}$ discurso sobre o valor da vida é o principal argumento contrário à realização do procedimento do abortamento - mesmo em casos autorizados por lei. Com observância própria e particular, a norma legal brasileira considera interrupção dolosa da gravidez, exceto nos casos de abortamento previsto pelo artigo 128 do Código Penal Brasileiro - gestação decorrente de estupro e risco de vida da gestante. $\mathrm{O}$ aborto é o ato deliberado que origina a inviabilidade do embrião ou do feto, independentemente da fase gestacional. Para o legislador, o que importa é a ação intencional que visa a agredir a vida intra-uterina, causando interrupção de seu desenvolvimento e provocando a morte fetal. Embora tenham se passado décadas desde a previsão do Aborto Legal no Código Penal Brasileiro, foi somente no final dos anos 1990 que a atenção ao abortamento nesses casos foi normatizada pelo Ministério da Saúde (2005), seguindo as orientaçōes das cúpulas internacionais e as orientações relacionadas à Atenção Integral à Mulher. ${ }^{7}$ 
Apesar da prescrição do Código Penal, em algumas ocasiōes o Poder Judiciário brasileiro tem autorizado a interrupção da gestação com anomalia fetal grave, incompatível com a vida extra-uterina. Desde 1992, juízes e promotores públicos autorizaram cerca de três mil casos de interrupção da gravidez de fetos anencéfalos no Brasil (PENNA, 2005, p. 96). Tais medidas não ocorreram sem tensões e debates públicos acirrados. A controvérsia em torno da descriminalização do aborto em determinadas circunstâncias, como na anencefalia, ou ampliando os dispositivos legais, vem ganhando espaço e atualmente é objeto de debate no Congresso Nacional.

Pesquisa recente (GALLI; GOMES, 2006), em serviços de referência no atendimento a vítimas de violência sexual, evidenciou o argumento da "objeção de consciência" por parte dos profissionais de saúde, como meio de se isentarem de prestar assistência às mulheres. Em outros termos, trata-se de uma dificuldade de realizar uma interrupção da gestação decorrente de estupro, uma vez que os médicos associam seu exercício profissional ao ato de salvar vidas. Tal dado indica a existência de uma barreira significativa ao acesso de mulheres a esta modalidade - legal - de abortamento. O procedimento é percebido pelos profissionais de saúde como interrupção da vida, quando inexiste um diagnóstico indicativo de inviabilidade fetal. Neste sentido, a interrupção da gravidez decorrente de estupro é apontada como um procedimento mais crítico, comparativamente à interrupção de gravidez de feto anencefálico, condição associada, entre equipes de saúde, à morte cerebral. Neste caso, não haveria mais vida a ser salva. (GALLI; GOMES, 2006; PORTO, 2006).

Devido à extrema complexidade do tema, em 2005 foi constituída a Comissão Tripartite, com a incumbência de discutir e propor uma revisão da legislação punitiva do aborto. A diretriz de gestão (gestar e gerir) (SOUZA-LIMA, 2002) foi posta em prática, conforme dispõe a Constituição Federal, para a formação da Comissão Tripartite: os 18 membros integrantes foram igualmente distribuídos, entre o Poder Executivo, o Poder Legislativo e a Sociedade Civil. Esta última contou com especialistas reconhecidos no campo dos movimentos sociais, da medicina e do direito (CUNHA, 2006). Foi elaborada a proposta da seguinte maneira:

Artigo $1^{\circ}$ - Toda mulher tem direito à interrupção voluntária de sua gravidez, realizada por médico e condicionada ao consentimento livre e esclarecido da gestante. Artigo $2^{\circ}$ - Fica assegurada a interrupção voluntária da gravidez em qualquer das seguintes condições: I - até doze semanas de gestação; II - até vinte semanas de 
gestação, no caso de gravidez resultante de crime contra a liberdade sexual; III no caso de diagnóstico de grave risco à saúde da gestante; IV - no caso de diagnóstico de malformação congênita incompatível com a vida ou de doença fetal grave e incurável. Ficam asseguradas, ainda, a realização do procedimento no âmbito do Sistema Único de Saúde, ou sua cobertura pelos planos privados de assistência à saúde.

A proposta foi incorporada ao Projeto de Lei no $1.135 / 1991$, que dispóe sobre a supressão do artigo 124 do Código Penal brasileiro, que impõe pena ao abortamento provocado pela gestante ou realizado com seu consentimento. ${ }^{8}$ Cunha (2006) observa, ainda, que diversos ajustes foram necessários para conduzir a um consenso. Três mudanças foram significativas: a passagem da nomeação da proposta de legalização para descriminalização; a abordagem do aborto como questão de saúde pública; e o tratamento do tema não mais pelo uso do termo aborto - por seu caráter estigmatizado - mas utilizando a expressão interrupção voluntária da gravidez. ${ }^{?}$

\section{Demarcação em processo: proposições parlamentares no Brasil}

A análise da proposição e tramitação de Projetos de $\operatorname{Lei}^{10}$ apresentados no âmbito legislativo ilustra os valores que cercam a determinação dos limites da vida. Partindo deste pressuposto, foi realizado um levantamento dos PLs sobre os temas aborto e eutanásia em três Casas Legislativas: a Câmara Federal e as Assembléias Legislativas dos estados de São Paulo e do Rio de Janeiro. Os PLs foram coletados independentemente de sua condição, o que significa que tanto aqueles ainda em tramitação quanto os já arquivados constituem objeto da investigação, por considerarmos relevante o exame dos debates em torno de cada um deles (GOMES et al., 2007). A coleta foi efetuada nas páginas das referidas Casas Legislativas, ${ }^{11}$ por meio dos instrumentos de busca ali disponíveis, totalizando 87 referentes ao aborto e 99 associados à eutanásia, a partir de três palavras-chave: doação de órgãos, morte encefálica e eutanásia.

Os 87 PLs coletados a partir do termo aborto focavam diretamente a temática ou a abordavam como questão subjacente. A complexidade emerge, principalmente, devido à existência de atores sociais com posicionamentos contrastantes em relação às mudanças na legislação. Os argumentos baseiam-se na defesa da vida do feto, na autonomia da mulher ou em prol de sua vida. Há 
proposições de um extremo a outro: por um lado, advogando um enrijecimento da lei, defendendo a criminalização irrestrita do aborto; por outro, postulando a descriminalização desta prática.

O levantamento demonstrou uma visível intensificação na proposição de PLs a partir da década de 1980. Nos anos 1940, foi apresentado apenas um; na década seguinte não houve propostas; na década de 1960, dois, e nos anos 1970, oito proposições. Nas décadas de 1980 e 1990, foram apresentados 20 e 31 PLs, respectivamente. Nos anos 2000 até o presente momento, já foram apresentados 25. Assinale-se que somente o PL no 1.104/1991, que não considera falta ao serviço por aborto, dentre todos os que tramitaram na Câmara Federal, passou por todas as etapas, sendo aprovado e transformado em Ordem Jurídica. Andalaft Neto e Rocha (2003) apresentam uma análise da legislação vigente e dos PLs apresentados à Câmara dos Deputados até o ano 2000. Nosso estudo corrobora suas conclusões, evidenciando que, mesmo com a crescente postura favorável à possibilidade de interrupção da gravidez nas proposições apresentadas nas últimas legislaturas, ainda há fortes reações contrárias.

O grande fluxo de projetos localiza-se a partir das décadas de 1980/1990, com uma grande variedade de temas. A polarização se torna então mais aparente. Os principais focos de reação - prós e contras - referem-se às convenções e aos pactos internacionais firmados nas duas décadas anteriores. ${ }^{12}$ Estes provocaram reflexos substanciais nos debates que influíram na elaboração da Lei no 9.263/1996, que dispõe sobre o Planejamento Familiar regulamentando o artigo $126^{13} \mathrm{da}$ Constituição Federal. Estas leis e normas seguiram provocando reações ainda na década seguinte. De 2000 até 2007, já foram apresentados 25 PLs, divididos em dois pólos excludentes e concorrentes: um identificado à descriminalização (despenalização) e outro à transformação do aborto em crime hediondo (aborto como "crime contra a vida").

O conteúdo da questão está em evidência em diversos fóruns de discussão. Recebeu maior visibilidade midiática a partir dos anos 1990, principalmente devido à repercussão do $\mathrm{PL} \mathrm{n}^{\circ} 1.135 / 1991$, que propõe a descriminalização, ao qual foram apensados diversos outros projetos, elaborados por parlamentares de distintas correntes, inclusive aquelas em oposição. A tramitação dos PLs, pela própria dinâmica das Casas Legislativas, se dá de maneira complexa. Quando um PL é apresentado com temática correlata a outro em tramitação é apensado 
ao original. Como exemplo, o PL no 7.235/2002, apresentado em 17 de outubro de 2002, pelo então presidente da Câmara dos Deputados, Dep. Severino Cavalcanti, com o objetivo de revogar o art. 128 do Código Penal (o que regula o abortamento permitido por lei), apensado ao PL no 1.135/1991, em 29 de outubro de 2002. Após ser apensado, houve pedido de desapensação, negado em 2005. Em janeiro 2007, com a mudança da legislatura, o PL foi arquivado pela Mesa Diretora da Câmara dos Deputados. Nos dois meses seguintes, foram apresentados cinco Requerimentos ${ }^{14}$ solicitando seu desarquivamento, o que se deu em 3 de abril de 2007, em resposta ao REQ no 213/2007.

Nesse processo ocorreram situações críticas, das quais ressaltamos três: 1) a edição da Norma Técnica para "Prevenção e Tratamento dos Agravos Resultantes da Violência Sexual contra Mulheres e Adolescentes" (Ministério da Saúde, 1999, revisada em 2005); ${ }^{15}$ 2) a instalação da Comissão Tripartite de Revisão da Legislação Punitiva sobre Aborto/ Audiência Pública, em 2005; e 3) a Audiência Pública sobre Aborto, em 27 de junho de 2007. Tal análise permite trazer à tona a controvérsia, os atores e as forças políticas que vêm atuando nos debates públicos sobre o tema.

No outro tema abordado em nossa pesquisa, os dados concernentes à eutanásia foram coletados a partir de três palavras-chave: eutanásia, morte encefálica e doação de órgãos, totalizando 99 PLs e 19 proposiçôes outras ${ }^{16}$ nas três Casas Legislativas investigadas. Os PLs levantados pela busca da expressão "doação de órgãos" surgem a partir da década de 1980, e são dirigidos tanto ao estabelecimento de regras para doação e extirpação de órgãos, tecidos e partes do corpo humano para fins de transplante, terapêuticos e científicos (como os PLs nos 1.169/1988 e 4.303/ 1989 da Câmara Federal) quanto ao estímulo à doação de órgãos. Os PLs nos 653/ 1988 e 55/1989, da Assembléia Legislativa do Estado de São Paulo, constituem exemplos desta última condição. Eles propõem, respectivamente, a concessão de tratamento prioritário para doadores em vida de órgãos, e estímulos especiais a residentes em território paulista que doarem, em vida, órgãos passíveis de serem transplantados, após sua morte.

A busca empreendida a partir da palavra-chave morte encefálica indica o surgimento de PLs e outras proposições a partir da década de 1990, estabelecendo critérios de constatação de morte encefálica, especialmente para fins de transplante de órgãos. A partir da aprovação da Resolução no 1.480, em 8 de agosto de 1997, pelo Conselho Federal de Medicina, que estabeleceu novos critérios de constatação 
de morte encefálica, há expressiva redução de proposições em torno de morte encefálica e aumento das que estimulam a doação de órgãos. Outro tema abordado pelos PLs concerne às normas de funcionamento da lista única de espera de transplantes de órgãos. ${ }^{17}$ Assim, os dois termos - doação de órgãos e morte encefálica - estão intimamente articulados, havendo, inclusive, coincidência de PLs na pesquisa nas três Casas Legislativas. ${ }^{18}$

A busca por estas palavras-chave evidenciou a normatização das condições técnicas de doação de órgãos e partes do corpo humano. Esse processo ocorreu sem conflitos ou apresentação de posições antagônicas, o que indica ampla aceitação dos distintos setores da sociedade - como movimentos sociais, profissionais de saúde e posicionamentos religiosos - em torno da doação e do transplante de órgãos. Este dado pode ser compreendido a partir de duas referências centrais na cosmologia ocidental contemporânea: o valor da vida e do indivíduo, às quais pode ser acrescentada outra idéia, também preeminente na contemporaneidade: a solidariedade.

Entretanto, cabe uma ressalva no que concerne ao estatuto da doação de órgãos: majoritariamente, as proposições objetivam estimular a doação. Quando a proposição se destina a tornar obrigatório constar em documentos oficiais referência ao portador ser ou não doador de seus órgãos, geralmente há debate. Como exemplo, o PL no 511/1996, apresentado na Assembléia Legislativa do Estado de São Paulo, que "dispõe sobre a obrigatoriedade de toda Carteira Nacional de Habilitação, expedida pelo Departamento Estadual de Trânsito de São Paulo, conter a opção expressa pelo seu portador quanto à doação ou não de seus órgãos", arquivado em 2000. Os dados evidenciam a preeminência do direito de autonomia individual no que diz respeito ao próprio corpo e seus desígnios, o que não se passa da mesma forma em relação a outros temas, como aborto e eutanásia.

Da mesma forma, como no caso do aborto, os PLs que abordam especificamente a eutanásia, em número de sete, revelam interessante debate em torno de determinados valores: vida, autonomia individual, poder médico e valores religiosos. Este grupo de proposições pode ser dividido em duas posições: uma favorável, na qual consta o projeto apresentado pelo médico e deputado Inocêncio Oliveira, em 1981 e 1983, com o seguinte texto: "permite ao médico assistente o desligamento dos aparelhos de um paciente em estado de coma terminal ou na omissão de medicamento que iria prolongar uma vida vegetativa, sem possibilidade 
de recuperar condições de vida sofrível, em comum acordo com os familiares e dá outras providências". Ambos foram arquivados. Vale notar que o autor da proposta é médico, e que seu texto postula amplos poderes ao médico assistente. Além destes, dois outros PLs foram apresentados pelo Dep. Gilvam Borges. O primeiro, de 1991, objetivava regulamentar a prática da eutanásia e o segundo, de 1993, propunha plebiscito sobre o tema. Como no caso dos PLs anteriores, estes também foram arquivados.

A posição contrária à eutanásia é apresentada pelo deputado Osmânio Pereira, com o mesmo texto, em 1994, 1995 e 2005, propondo a classificação do aborto e da eutanásia como crimes hediondos. O projeto de 1994 foi arquivado, o do ano seguinte foi retirado pelo deputado e o de 2005 está em julgamento. Cabe referir que o autor é católico, pertencente à Renovação Carismática Católica. A partir destes PLs, é possível concluir que as duas linhas de propostas representam posições oriundas de distintos referenciais: a favorável é justificada em argumentação médica, baseada em critérios da ciência - em especial, da biológica e biomédica -, enquanto a contrária está alinhada a preceitos religiosos, que, no entanto, também acionam argumentos biológicos e científicos em seus argumentos. Os atores dessa interlocução - mesmo que tensa - não estão caracterizados por uma lógica de oposição binária, na qual ou se associam à laicidade ou à religião. Os atravessamentos são evidentes e constantes no grupo filiado às correntes religiosas contrárias à descriminalização. Atores centrais do debate são médicos e juristas; além disso, especialistas das áreas biomédica e jurídica são convocados com o intuito de legitimar ambas as teses (GOMES et al., 2007).

Outros projetos, emendas e leis estão em constante discussão no Legislativo. Os debates e controvérsias não se restringem às bancadas dos partidos políticos, mas incorporam pontos de vista de diferentes segmentos da sociedade civil. Da pauta de discussão constam diversas propostas, com objetivos díspares: descriminalização da interrupção da gravidez até a 12a semana; punição para casos de aborto resultante de estupro; permissão de laqueadura tubária no parto e abortamento em caso de cesariana anterior; tornar o aborto e a eutanásia crimes hediondos, tendo como base a inviolabilidade do direito à vida (art. 266, parágrafo 7 da Constituição Federal); isenção de punição ao aborto em casos de anencefalia fetal e aborto terapêutico com comprovação por laudos de dois médicos; supressão da lei que criminaliza a prática do aborto. 
Na esfera da saúde há posicionamentos contrários no que tange ao início da vida. A plenária final da $13^{\text {a }}$ Conferência Nacional de Saúde, em 18 de novembro de 2007, evidencia a presença de distintas lógicas. Foi então decidido, por unanimidade de votos, o incentivo à pesquisa com células-tronco embrionárias no país. ${ }^{19}$ Por outro lado, foi rejeitada a proposição de descriminalização do aborto. Ambas as questôes se referem não apenas à determinação do início da vida, mas indicam o dilema entre os direitos de autonomia da mulher - ou do casal, no caso das células-tronco embrionárias - e os direitos do embrião/feto. O debate está centrado no direito de proteção à vida, uma vez que a inviolabilidade da vida humana é garantida pela Constituição Federal. Deste modo, o que está em questão é a determinação do momento do início da vida. A partir deste ponto, a polêmica entre os posicionamentos laicos e religiosos se acirra.

O Estado brasileiro é laico e dedica-se a proteger o direito à liberdade de crença. O princípio de sacralidade da vida assegura valor moral à existência humana e fundamenta os mecanismos sociais que garantem o direito de estar vivo. Trata-se de um princípio laico, também presente em diferentes códigos religiosos, que não possui o mesmo significado do princípio da santidade da vida (DINIZ, 2006a a p. 1.740). Reconhecer o valor moral da existência humana não é o mesmo que reconhecer sua intocabilidade. De acordo com Diniz (2006b, p. 1.742), o que está expresso no ordenamento jurídico brasileiro é o princípio da sacralidade da vida humana e não o princípio da santidade da vida humana. O valor moral compartilhado é o que reconhece a vida humana como um bem, mas não como um bem intocável por razões religiosas. Entretanto, a socialização dos profissionais de saúde ${ }^{20}$ entrelaça ambos os conceitos, de modo a sobrepor valores privados e metafísicos acerca do sentido da existência, de seu início e seu término (em outros termos, da morte) a princípios coletivos, como da sacralidade da vida e da autonomia (DINIZ, 2006b, p. 1.742).

Os temas do aborto e da eutanásia - quando não há mais possibilidade de cura da doença - provocam dilemas morais e intensos debates nos distintos contextos. Da mesma forma como se dá em relação ao caso da Lei de Biossegurança de 2005, quando há controvérsia em torno de certas decisões, a ciência, a medicina e seus profissionais são convocados a expor seus argumentos. Entretanto, como a Audiência Pública do Supremo Tribunal Federal evidenciou, não há, via de regra, uma única posição - seja dos religiosos, seja dos representantes dos saberes científicos. 
No debate em torno do aborto e da eutanásia novos termos são cunhados pelo aparato médico, seja no que tange à gestão do último período de vida, seja ao abortamento. As distintas possibilidades de interpretação acerca das expressões "distanásia" e "ortotanásia" constituem indício da complexidade da temática associada à eutanásia. Em relação ao aborto, as ações e reações são semelhantes: "antecipação terapêutica do parto" ${ }^{21} \mathrm{e}$ "interrupção da gravidez" são termos que passaram a coexistir com o aborto, especialmente em casos de anencefalia ou malformação fetal, sendo incorporado à linguagem parlamentar, favorável ou contrária à descriminalização. O PL no 5.166/2005, posteriormente apensado ao PL no $1.135 / 91$, por exemplo, postula a punição criminal da chamada antecipação terapêutica do parto, em gestação de feto anencéfalo. Esta é uma resposta direta às recorrentes autorizaçōes judiciais concedidas às gestantes que solicitam ao judiciário a interrupção da gravidez nesses casos. Indo além, trata-se de uma reação à tendência mais ampla a aceitar e positivar a realização do aborto em casos de malformação fetal, ampliando os permissivos legais. A tese defendida pelos parlamentares religiosos é de criminalização, não apenas de um tipo de abortamento, como propõe o PL no 1.135/1991 - provocado por terceiros sem consentimento da gestante mas de toda e qualquer modalidade.

\section{(In)definições de vida e morte: limites em debate}

Eutanásia e aborto têm-se tornado cada vez mais temas públicos importantes, o que pode ser compreendido de diversas formas: maior capacidade da tecnologia médica de manutenção da vida extra-uterina em caso de recém-nascidos pré-termo e de produzir um prolongamento da vida; discussão sobre o término da vida a partir da epidemia de Aids e a crescente ênfase do discurso da autonomia nas sociedades ocidentais contemporâneas (MENEZES, 2004, p. 37).

Como mencionado, a determinação dos limites da vida varia segundo o contexto histórico, social e cultural. Portanto, a cada reivindicação de mudança das normas referentes ao início e ao final da vida, as diversas perspectivas necessariamente estarão em evidência. Neste início de século, vêm-se apresentando crescentes demandas em prol da legalização do aborto - em diversos países e, sobretudo, nos católicos, como Espanha, Portugal e México - e da interrupção do chamado encarniçamento terapêutico (ou tratamento fútil) ao final da vida. 
Os argumentos da Igreja Católica e de outras cristãs centram-se na santidade da vida humana:

A vida humana é o fundamento de todos os bens, a fonte e a condição necessária de toda a atividade humana e de toda a convivência social. Se a maior parte dos homens considera que a vida tem um caráter sagrado e admite que ninguém pode dispor dela a seu bel-prazer, os crentes vêem nela também um dom do amor de Deus, que eles têm a responsabilidade de conservar e fazer frutificar. (Sagrada Congregação para a Doutrina da Fé: Declaração sobre a Eutanásia)

Desta última consideração derivam diversas conseqüências, dentre as quais se destacam as seguintes: atentar contra a vida humana significa se opor ao amor de Deus; todos os homens têm o dever de conformar sua vida com a vontade do Criador; a morte voluntária ou suicídio é tão inaceitável quanto o homicídio. ${ }^{22}$

No discurso religioso percebe-se a referência ao primado do indivíduo como ser natural, o que pode ser ilustrado por um panfleto, distribuído no Primeiro Ato Público em Defesa da Vida, em março de 2007, na Praça da Sé (cidade de São Paulo). Em seu texto consta que "a vida humana é uma dádiva de Deus, direito natural anterior ao Estado, que o deve reconhecer como direito fundamental”. Nesta medida, observa-se que o próprio discurso religioso contém os princípios do que designamos de cosmologia moderna. Parte-se do pressuposto de que o argumento religioso não está dissociado do contexto mais amplo da sociedade, uma vez que mantém uma constante e complexa relação com as diferentes esferas que a constitui.

As posiçōes na controvérsia em torno dos limites da vida representam basicamente dois grupos: de um lado, os religiosos e, de outro, movimentos sociais, organizações não-governamentais e setores da sociedade que veiculam determinados valores, caros à cultura ocidental contemporânea, tais como liberdade e autonomia individual, subjetivismo e naturalismo (DUARTE et al., 2006, p. 18).

O caráter religioso dos discursos dos parlamentares extrapola o fundamento confessional, modelado pela crença na origem divina da "vida". Cada vez mais os argumentos se pautam pela mediação entre o religioso e a linguagem médica e jurídica - que representam valores laicos por excelência. Parlamentares-religiosos vinculados ao debate são ou tornam-se especialistas nos temas e nos procedimentos legislativos que possibilitam ou impedem a aprovação de projetos no parlamento. Nos dois lados da interlocução são determinados atores que assumem e levam 
adiante a polêmica sobre criminalização ou descriminalização. Ponto que os une é o compromisso, ainda que oposto, de discutir publicamente a questão, enquanto grande parte dos parlamentares não se filia a qualquer corrente e aguarda os acontecimentos. Por outro lado, os posicionamentos das instituiçóes religiosas que participam dos debates não são passíveis de homogeneização. Embora reconheçamos a mobilização de movimentos internos, como é o caso das Católicas pelo Direito de Decidir, que são contrárias a determinadas orientações institucionais, o estudo privilegiou as orientaçôes oficiais e manifestadas nos posicionamentos dos parlamentares opositores ao aborto e à eutanásia.

A autonomia individual - referência central na sociedade ocidental contemporânea - é veiculada pelos movimentos em prol do "direito do nascituro", da "morte com dignidade" ou do "direito de morrer", e desempenha importante papel no debate em torno dos temas aqui abordados - eutanásia e aborto. $\mathrm{O}$ direito a se manter vivo é, certamente, um dos direitos humanos mais fundamentais e de consenso entre os diversos posicionamentos - sejam eles provenientes de instituiçôes religiosas, de instâncias jurídicas ou da classe médica. A vida humana é um valor maior e deve ser protegido pela legislação.

Entretanto, as distintas posições indicam que não há consenso acerca do sentido da vida e/ou da morte. Diferentes noções de bem, de felicidade e de dignidade apresentam-se nesta polêmica. Cabe frisar que a instituição religiosa afirma a santidade da vida humana como bem maior e, em decorrência deste estatuto, condena qualquer ação capaz de alterar o "curso natural" da vida e da morte. No entanto, face às possibilidades de intervenção médica, com recursos tecnológicos capazes de prolongar a vida, a condição "natural" passa a ser cada vez mais passível de discussão, deixando algumas brechas - ainda que sutis - para o diálogo com determinadas correntes religiosas, inclusive as cristãs. As tensões que envolvem as definições dos limites da vida e da morte seguem contínuas e inconclusas.

\section{Referências}

ANDALAFT NETO, Jorge; ROCHA, Maria Isabel. A questão do aborto: aspectos clínicos, legislativos e políticos. In: BERQUÓ, Elza (Org.). Sexo e vida: panorama da saúde reprodutiva no Brasil. Campinas: Unicamp, 2003.

BOLTANSKI, Luc. La condition foetale: une sociologie de l'engendrement e de l'avortement. Paris: Gallimard, 2004. 
CAMARGO JUNIOR, Kenneth Rochel. Biomedicina, saber \& ciência: uma abordagem crítica. São Paulo: Hucitec, 2003.

CHAZAN, Lilian C. "Meio quilo de gente": produção do prazer de ver e construção da pessoa fetal mediada pela ultra-sonografia: um estudo etnográfico em clínicas de imagem na cidade do Rio de Janeiro. 2005. Tese (Doutorado em Saúde Coletiva)-Instituto de Medicina Social, Universidade do Estado do Rio de Janeiro, Rio de Janeiro, 2005.

COSTA, Ana Maria. Desenvolvimento e implantação do PAISM no Brasil. In: GIFFIN, Karen M.; COSTA, Sarah (Org.). Questôes da saúde reprodutiva. Rio de Janeiro: Fiocruz, 1999. p. 319-355.

CUNHA, Anna Lúcia Santos da. Revisão da legislação punitiva do aborto: embates atuais e estratégias políticas no parlamento. In: SEMINÁRIO INTERNACIONAL FAZENDO GÊNERO, 7., 2006, Florianópolis. Anais... Florianópolis: UFSC, 2006.

DINIZ, Debora. Aborto e saúde pública no Brasil. Cadernos de Saúde Pública, v. 23, n. 9, p. $1992-$ 1993, set. 2007.

. Fórum: o fim da vida. Cadernos de Saúde Pública, Rio de Janeiro, v. 22, n. 8, p. 17391740, ago. 2006 .

. Quando a morte é um ato de cuidado: obstinação terapêutica em crianças. Cadernos de Saúde Pública, Rio de Janeiro, v. 22, n. 8, p. 1741-1748, ago. 2006 b.

DUARTE, Luiz Fernando Dias. Ethos privado e justificação religiosa: negociações da reprodução na sociedade brasileira. In: HEILBORN, Maria Luiza et al. Sexualidade, familia e ethos religioso. Rio de Janeiro: Garamond, 2005. p. 137-176.

. Indivíduo e pessoa na experiência da saúde e da doença. Ciência \& Saúde Coletiva, Rio de Janeiro, v. 8, n. 1, 2003. p. 173-183.

. Pessoa e indivíduo. In: LIMA, Antonio Carlos Souza (Org.). Antropologia \& direito: contribuições antropológicas a um diálogo interdisciplinar. No prelo.

DUARTE, Luiz Fernando Dias; GIUMBELLI, Emerson A. As concepções de pessoa cristã e moderna: paradoxos de uma continuidade. Anuário antropológico, n. 93, p. 77-111, 1994.

DUARTE, Luiz Fernando Dias et al. Família, reprodução e ethos religioso: subjetivismo e naturalismo como valores estruturantes. In: DUARTE, Luiz Fernando Dias et al. (Org.). Família e religião. Rio de Janeiro: Contracapa, 2006. p. 15-50.

DUMONT, Louis. O individualismo: uma perspectiva antropológica da ideologia moderna. Rio de Janeiro: Rocco, 1985.

EVANS-PRITCHARD, E. E. Antropologia social. Lisboa: Edições 70, 1985.

FOUCAULT, Michel. O nascimento da clínica. Rio de Janeiro, Forense Universitária, 1977.

FRANÇA, Genival Veloso. Medicina legal. Rio de Janeiro: Guanabara Koogan, 2004. 
GALLI, Beatriz; GOMES, Edlaine C. Representações dos profissionais de saúde em relação ao aborto: entre direitos e deveres na atenção. In: SEMINÁRIO INTERNACIONAL FAZENDO GÊNERO, 7., 2006, Florianópolis. Anais... Florianópolis: UFSC, 2006.

GOMES, Edlaine Campos. A religião em discurso: a retórica parlamentar sobre o aborto. In: . Relatório de pesquisa: "Entre o público e o privado: a influência dos valores religiosos na tramitação de projetos de lei no Brasil”. São Paulo: PROSARE/CCR, 2007.

GOMES, Edlaine Campos; NATIVIDADE, Marcelo T.; MENEZES, Rachel Aisengart; NOGUEIRA, Diana Lima. Relatório de pesquisa: "Entre o público e o privado: a influência dos valores religiosos na tramitação de Projetos de Lei no Brasil”. São Paulo: PROSARE/ CCR, 2007.

GOMES, Luiz Flávio (Org.). Constituição federal, código penal, código de processo penal. São Paulo: Revista dos Tribunais, 2001.

HENNEZEL, Marie. Nous ne nous sommes pas dit au revoir. Paris: R. Lafont, 2000.

. Propositions pour une vie digne jusqu'au bout. Paris: Seuil, 2004.

HERZLICH, Claudine. Os encargos da morte. Rio de Janeiro: IMS/UERJ, 1993.

HOWARTH, Glennys; Leaman, Oliver (Ed.). Encyclopedia of death and dying. Londres: Routledge, 2001.

KAUFMAN, Sharon R.; MORGAN, Lynn M. The anthropology of the beginings and ends of life. Annual Review of Anthropology, v. 34, p. 317-41, 2005.

LIMA, Antônio Carlos de Souza (Org.). Gestar e gerir: estudos para uma antropologia da administração pública no Brasil. Rio de Janeiro: Relume Dumará, 2002.

LOCK, Margaret. Living cadavers and the calculation of death. Body \& Society, v. 10, n. 2-3, p. 135-152, 2004.

Twice dead: organs transplants and the reinvention of death. Berkeley: University of Califórnia Press, 2002.

LUNA, Naara. As novas tecnologias reprodutivas e o estatuto do embrião. Revista Gênero, Niterói, v. 3, n. 1, p. 83-100, 2002.

. Pessoa e parentesco nas novas tecnologias reprodutivas. Estudos Feministas, v. 2, p. 389413, 2001.

. Provetas e clones: uma antropologia das novas tecnologias reprodutivas. Rio de Janeiro:

Fiocruz, 2007.

MAUSS, Marcel. Uma categoria do espírito humano: a noção de pessoa, a de "Eu”. In: MAUSS, M. Ensaios de sociologia. São Paulo: Perspectiva, 2003b. 
. Efeito físico no indivíduo da idéia de morte sugerida pela coletividade. In: MAUSS, M. Ensaios de sociologia. São Paulo: Perspectiva, 2003a.

MENEZES, Rachel Aisengart. Dificeis decisóes: etnografia de um Centro de Tratamento Intensivo. Rio de Janeiro: Fiocruz, 2006.

. Em busca da boa morte: antropologia dos cuidados paliativos. Rio de Janeiro: Garamond/ Fiocruz, 2004.

PENNA, Maria Lúcia Fernandes. Anencefalia e morte cerebral (neurológica). Physis - Revista de Saúde Coletiva, Rio de Janeiro, v.15, n. 1, p. 95-106, jun. 2005.

PORTO, Rozeli. O aborto em destaque: representações dos profissionais da saúde sobre o aborto seletivo em um hospital público no sul do Brasil. Comunicação apresentada na 27a. Reunião Brasileira de Antropologia, Goiânia, 2006.

Sagrada Congregação para a Doutrina da Fé: Declaração sobre a Eutanásia. http://www.vatican.va/ r o m a n_ curia/congregations/cfaith/documents/ rc_con_cfaith_doc_19800505_euthanasia_po.html. Acesso em 14/07/2007.

SALEM, T., As novas tecnologias reprodutivas: o estatuto do embrião e a noção de pessoa, Mana, v. 3, n. 1, 1997.

TURNER, Victor. O processo ritual: estrutura e anti-estrutura. Petrópolis: Vozes, 1974.

WEBER, Max. A ética protestante e o espirito do capitalismo. São Paulo: Pioneira, 1992.

\section{Notas}

${ }^{1}$ Dados concernentes à Pesquisa "Entre o público e o privado: influência dos valores religiosos na proposição e tramitação de Projetos de Lei" (Núcleo de pesquisa "Sujeito, interação e mudança: problemas e perspectivas na sociedade brasileira”, PPGAS/ Museu Nacional/UFRJ), coordenada por Luiz Fernando Dias Duarte e financiada pelo CCR/Prosare, de setembro de 2006 a agosto de 2007. Agradecemos especialmente a leitura da primeira versão deste artigo e as ricas sugestões de Naara Luna.

${ }^{2}$ De acordo com Duarte (2003, p. 174), "a questão da determinação social ou cultural das representações de 'pessoa' já se podia entrever no pensamento dos pais fundadores das ciências humanas no século XIX. [...] O primeiro texto explícito sobre o que se pode chamar hoje de 'construção social da pessoa' é o de Marcel Mauss sobre a 'noção de Pessoa', publicado em 1938. [...] Um pouco antes de Mauss produzir o texto citado, seu mestre Durkheim publicara um texto circunstancial de pouca ressonância na época, mas que pode ser hoje considerado um dos primeiros a nomear em seu pleno sentido sociológico uma categoria analítica importante para a compreensão das formas moderna da pessoa: o 'individualismo"”.

${ }^{3}$ Em concordância com Duarte (2005, p. 158), compreendemos cultura ocidental contemporânea como um constructo cosmológico, no qual a idéia de natureza desempenha papel crucial na ordenação dos horizontes modernos. Nesta perspectiva, apresenta-se uma valoração nova e radical da realidade 
física do mundo, apreensível pela razão humana (vista como natural) e oposta ao privilégio tradicional da sobrenatureza e da transcendência moral. Nesta concepção, é atribuída preeminência a duas instâncias: a objetividade da natureza e a autonomia da condição humana.

${ }^{4}$ Segundo Duarte (no prelo), a pessoa representa os entes socialmente relevantes imersos em sua rede de relações e em sua trama densa de atribuiçôes e significados, enquanto o indivíduo representa as unidades mínimas, pensadas como autônomas, da espécie humana. Sobre o tema, ver Dumont (1985).

${ }^{5}$ No entanto, isto não ocorre em todas as sociedades contemporâneas. A ciência como meio de acesso às verdades e a definição da morte de uma pessoa mediante diagnóstico médico de morte encefálica não foram aceitos no Japão, país com alto nível econômico e tecnologia sofisticada. Diversamente dos Estados Unidos, no qual há uma crença disseminada nas verdades médicas e científicas, no Japão o aparato médico é objeto de desconfiança, especialmente a partir do primeiro caso de transplante cardíaco, em 1968 (LOCK, 2002, p. 130), que provocou amplo debate público e um processo legal em torno das evidências de morte cerebral do doador e de negligência na assistência médica.

${ }^{6}$ Face aos avanços tecnológicos aplicados à assistência em saúde, direcionados ao prolongamento da vida, aliado às crescentes reivindicaçôes da sociedade mais ampla - em diversos países do Ocidente - em prol do direito de morrer "com dignidade", a Igreja Católica publicou a Declaração de Eutanásia em 1980.

${ }^{7}$ Como observa Costa, "no entanto, os serviços que estão implantados surgiram das reivindicaçôes e das lutas feministas. Não há nenhum serviço no Brasil que tenha sido implantado por decisão do gestor de saúde ou do secretário estadual ou municipal" (COSTA, 1999). Cabe ressaltar a grande dificuldade de implementação desses serviços, em especial, no que concerne ao abortamento previsto em lei, que tem na alegação de objeção de consciência pelos profissionais de saúde um dos principais impeditivos para a efetivação do atendimento (GALLI; GOMES, 2006).

${ }^{8}$ O Código Penal Brasileiro (Decreto-Lei no 2.848 , de 7 de dezembro de 1940) aborda o tema aborto em seus artigos 124 a 128. Regula o aborto sob distintas óticas: I - art. 124, $1^{\text {a }}$ parte, aponta o aborto provocado pela gestante ou o auto-aborto; II - art. 124, $2^{\text {a }}$ parte, revela o consentimento da gestante; III - art. 125 trata do aborto provocado por outrem, sem consentimento da gestante; IV - art. 126 apresenta o provocado por outrem, com consentimento da gestante ou consensual; V - art. 127 explicita o aborto qualificado. No art. 128, o CPB dispóe sobre os casos em que a realização do aborto não é penalizada (risco de morte e estupro).

${ }^{9}$ Ressalte-se que a estratégia de recorrer às estatísticas do SUS para dimensionar, em termos quantitativos, o quadro de abortamentos no país, parece não ter surtido efeito nos posicionamentos contrários à descriminalização, principalmente os de cunho religioso. Um dado ilustrativo foi a maciça campanha dirigida pela Igreja Católica contra a então deputada federal Jandira Feghali, na fase final do processo eleitoral de 2006, quando disputava uma cadeira para o Senado Federal. A divulgação da associação entre Feghali e a reforma da lei do aborto entre os católicos parece estar diretamente associada a seu fracasso no pleito. O período eleitoral foi acompanhado pelo Projeto "Entre o público e o privado: influência dos valores religiosos na proposição e tramitação de Projetos de Lei”, por meio de coleta de reportagens de jornais de grande circulação. A análise desse material possibilita tais conclusões (GOMES et al., 2007). 
${ }^{10}$ A partir daqui passamos a citar Projeto de Lei como PL.

${ }^{11}$ www.camara.gov.br; www.alerj.rj.gov.br; www.alesp.sp.gov.br

${ }^{12}$ Convenção Internacional sobre a Eliminação de Todas as Formas de Discriminação Racial - 1965; Pacto Internacional sobre Direitos Civis e Políticos - 1966; Pacto Internacional sobre Direitos Econômicos, Sociais e Políticos - 1966; Convenção sobre a Eliminação de Todas as Formas de Discriminação Contra a Mulher - 1979 - Comitê CEDAW aprovado pela Assembléia Geral das Nações Unidas. Nos anos 1980 e 1990, foram realizados outros encontros internacionais significativos: Convenção Internacional contra a Tortura e outros Tratamentos ou punições cruéis, desumanos ou degradantes - 1984; Convenção sobre os Direitos da Criança - 1989; Cúpula da Terra/ECO - 1992; Conferência de Direitos Humanos de Viena - 1993; Plano de Ação da Conferência Mundial de População e Desenvolvimento no Cairo - 1994; Plataforma de Ação da IV Conferência Mundial da Mulher de Pequim - 1995.

${ }^{13}$ Art. 126, parágrafo 7, declara: "fundado nos princípios da dignidade da pessoa humana e da paternidade responsável, o planejamento familiar é livre decisão do casal, competindo ao Estado propiciar recursos educacionais e científicos para o exercício desse direito, vedada qualquer forma coercitiva por parte de instituições oficiais ou privadas".

${ }^{14} \mathrm{~N}^{\circ}$ s $213,250,379,411,465$ e 591.

${ }^{15}$ A citada Norma Técnica e sua posterior implementação são de extrema relevância para a contextualização do tema. Ela trata especificamente do vínculo entre aborto e atenção humanizada em saúde, concernente à atuação dos profissionais da área atuantes nos serviços de referência que atendem a mulheres e adolescentes vítimas de violência sexual e suas conseqüências, dentre as quais o abortamento previsto em lei. É o primeiro documento elaborado após a vigência da lei, presente no Código Penal Brasileiro de 1940 que, finalmente, normatiza a atenção e os procedimentos relativos ao abortamento em caso de estupro.

${ }^{16}$ Como requerimento, requerimento de informação, sugestão, projeto de lei complementar, projeto de decreto legislativo e projeto de resolução.

${ }^{17}$ Como o PL no 4.165/2004, apresentado na Câmara Federal, que "altera a Lei no 9.434, de 4 de fevereiro de 1997, a Lei dos transplantes, para inserir diretrizes sobre o funcionamento da lista única de espera".

${ }^{18}$ Como exemplo, o PL no 2.617/1992, proposto na Câmara Federal, "define morte do tronco encefálico (morte cerebral) através de critérios clínico-neurológicos, dirimindo dúvidas em pacientes críticos, em estado de coma, grau três (03) na escala de coma Glasgow, com ventilação mecânica e potenciais doadores para transplantes de órgãos e tecidos".

${ }^{19} \mathrm{O}$ caso da Lei de Biossegurança no 11.105 , aprovada em 2005, ilustra este debate: ela autoriza a pesquisa com células-tronco de embriões, obtidos por fertilização in vitro, mantidos em congelamento há mais de três anos, desde que haja consentimento expresso dos pais. Atualmente, esses embriōes fertilizados, mas não implantados no útero das mães, são descartados ao completarem quatro anos de congelamento. De acordo com pesquisadores que defendem o uso deste material, as células-tronco embrionárias - ao contrário das adultas - se mostram mais eficazes para dar origem a qualquer tecido 
do corpo. Dois meses após a aprovação desta lei, Fonteles, então Procurador-geral da República, impetrou uma Ação Direta de Inconstitucionalidade no Supremo Tribunal Federal, contra o uso dessas células embrionárias em pesquisa e terapia. Ressalte-se que a ação é apoiada pela Confederação Nacional de Bispos do Brasil. Esta ação foi aceita em 2006 por Carlos Britto, Ministro do Supremo Tribunal Federal, que convocou uma audiência pública - a primeira na história desse tribunal - com exposição de cientistas, pesquisadores e médicos, com amplo conhecimento sobre o tema, para apresentar suas posiçôes. Estava em debate se o quinto artigo dessa lei seria inconstitucional, por atentar contra a vida. Os especialistas - favoráveis e contrários à lei - dividiam-se entre a defesa dos valores religiosos (pautados na santidade e defesa da vida desde a fertilização) e dos laicos (direitos humanos, em especial, o direito de autonomia individual).

${ }^{20}$ Para os médicos, a morte é considerada uma expressão do fracasso de sua atuação (HERZLICH, 1993, p. 7). Recentemente, a mídia vem divulgando demandas pela eutanásia, o que pode ser ilustrado pelos casos de Terri Schiavo, Ramón Sampedro, Inmaculada Echevarría, Vincent Humbert, entre outros. Organizaçôes não-governamentais são criadas em distintos países em prol dessa causa, como a espanhola Asociación Derecho a Morir Dignamente, evidenciando um movimento social direcionado à avaliação e, de acordo com a situação, prestar assistência às demandas de interrupção da vida. No Brasil, profissionais de saúde denunciam que a prática da eutanásia em unidades de tratamento intensivo ocorre sem controle institucional (Jornal Folha de São Paulo, 20/02/2005).

${ }^{21}$ Cabe ressaltar que, para a medicina, é considerado aborto somente o feto com mais de 20 semanas ou com peso acima de 500 gramas de peso corporal. Além desses limites, são tratados como seres viáveis, com possibilidade de autonomia em relação ao corpo da mãe, mediante suporte tecnológico para manutenção de sua vida. Neste sentido, o uso do termo "antecipação terapêutica do parto" está em consonância com as diretrizes, e é estendido à assistência da gestante e do feto. No entanto, os usos e as ressignificações dos termos não estão dissociados do contexto mais amplo. Segundo a Resolução $\mathrm{n}^{\circ}$ 1.601/2000, o Conselho Federal de Medicina dispõe que é obrigação do médico fornecer atestado de óbito do feto somente "quando a gestação tiver duração igual ou superior a 20 semanas ou o feto tiver peso corporal igual ou superior a 500 (quinhentos) gramas e/ou estatura igual ou superior a 25 cm". Disponível em: www.cremesp.org.br/?siteAcao=Jornal\&id=547. Acesso em: 8 dez. 2007. Esta determinação não está livre de intensas controvérsias.

${ }^{22}$ Luna (2002, p. 93), ao analisar a identidade e o estatuto do embrião em documentos oficiais da Igreja Católica, observa que "a concepção do ser humano como uma unidade de corpo e alma lhe confere o atributo de dignidade pessoal desde o início da vida na fertilização. [...] Está presente em todos os documentos uma ontologia substancialista que supóe que o estatuto de pessoa seja intrínseco ao embrião desde o início da existência física, dada a conjunção de corpo e alma”. 


\section{Abstract}

Abortion and euthanasia: contemporary
issues on the limits of life

This article analyzes the controversy surrounding what can be established as the limit of life, from the presumption that the frontier marks between life and death involve cultural, social, religious and political issues referred to personhood management. Debates about abortion and euthanasia make it clear that moral concepts on individual rights can be standardized in each context. These themes reveal beyond new medical technology creation and development, focused on assisted fertilization, fetal medicine and maintaining life artificially, either for premature babies or patients without possibilities of cure - values and viewpoints, often opposed. From the survey of law projects, presented within Brazilian legislative field, opposite positions were revealed, from religion and defenders of individual autonomy, which illustrates the contemporary dilemmas on the limits of life.

> Key words: life; death; abortion; euthanasia. 